\title{
HUBUNGAN PERILAKU CARING PERAWAT DENGAN TINGKAT HARAPAN SEMBUH PADA PASIEN KANKER YANG MENJALANI PROGRAM KEMOTERAPI DI RUMAH SAKIT BALADHIKA HUSADA JEMBER \\ The Relationship Between Nurses Caring Behavior and Recovery Hope Level of Cancer Patients Undergoing Chemotherapy Program at Baladhika Husada Hospital in Jember
}

\author{
Alvinda Apriliatul Jannah, Anisah Ardiana, Retno Purwandari \\ Fakultas Keperawatan Universitas Jember \\ Naskah masuk: 21 April 2020 Perbaikan: 13 Juli 20202020 Layak terbit: 17 Juli 2020 \\ https://doi.org/10.22435/hsr.v23i3.3123
}

\begin{abstract}
ABSTRAK
Harapan adalah hal krusial pada pasien kanker. Harapan dapat ditingkatkan dengan pemberian dukungan sosial yang bisa didapat dari perilaku caring perawat. Tujuan dari penelitian ini adalah untuk menganalisis hubungan perilaku caring perawat dengan tingkat harapan sembuh pasien kanker yang menjalani program kemoterapi di Rumah Sakit Baladhika Husada Jember. Penelitian ini menggunakan metode cross sectional dan 112 responden didapatkan dengan teknik sampel purposive sampling. Data didapatkan melalui kuesioner CBI-24 dan kuesioner skala harapan. Analisis pada penelitian ini menggunakan uji korelasi Kendall Tau B (т). Hasil menunjukkan terdapat hubungan antara perilaku caring perawat dengan tingkat harapan sembuh pasien kanker yang menjalani program kemoterapi di Rumah Sakit Baladhika Husada Jember ( $p$ value $<0,001 ; \tau=0,375$ ). Perilaku caring perawat dapat meningkatkan kenyamanan pasien dan membuat pasien lebih semangat menjalankan terapi yang dijalani. Pasien merasa dinilai dan mendapatkan informasi lebih dari perawat. Maka dari itu, harapan sembuh pasien dapat meningkat. Kesimpulan dari penelitian ini adalah perilaku caring perawat dapat meningkatkan harapan sembuh pasien kanker.
\end{abstract}

Kata Kunci: harapan, harapan sembuh, perilaku caring perawat

\section{ABSTRACT}

Hope is a crucial issue in patients with cancer. Hope can be increased by providing social support. Social support can be obtained from the nurses caring behavior. This research aimed to analyze the relationship between nurses caring behavior and recovery hope level of cancer patients undergoing chemotherapy program at Baladhika Husada Hospital in Jember. A cross-sectional study was conducted to 112 respondents using the Caring Behavior Inventory (CBI-24) questionnaire and Scale of Hope. The data were analyzed applying the Kendall Tau B (T) correlation. The results showed that there was a relationship between nurses caring behavior with the level of recovery expectancy of cancer patients undergoing chemotherapy programs at Baladhika Husada Hospital in Jember ( $p$-value <0.001; $\tau=0.375$ ). Nurse caring behavior increases patient comfort and makes patients more enthusiastic about undergoing therapy. Patients feel valued and get more information from nurses. Therefore, the patient's recovery hopes can increase. This study concludes that nurses caring behavior can increase the expectation of recovery of cancer patients.

Keywords: Hope, Hope of recovery, Cancer, Nurses Caring Behavior

Korespondensi:

Alvinda Apriliatul Jannah

Fakultas Keperawatan Universitas Jember

E-mail: alvindaaprilia47@gmail.com 


\section{PENDAHULUAN}

Kanker merupakan penyakit kronis yang dapat mengakibatkan berbagai masalah biologis, psikologis, sosial dan spiritual (Sulisno dan Sari, 2016). Pasien kanker yang sedang melakukan terapi pengobatan terbukti mengalami masalah kesehatan fisik dan psikologis akibat penurunan kondisi fisik yang disebabkan oleh penyakit dan efek samping terapi yang sedang dijalani (Wahyuni, Dwi; Huda Nurul; Utami, 2015). Pasien kanker mengemukakan bahwa ia mengalami kekhawatiran akan masalah-masalah yang akan dihadapinya pada saat ia mengalami kanker seperti ketergantungan, hopelessness atau keputusasaan, menjadi beban bagi orang lain, kehilangan peran sosial dan merasa tidak berguna (Wei dkk., 2016). Breatbart melakukan wawancara terhadap 300 pasien kanker dan ditemukan bahwa sebagian besar pasien kanker membutuhkan bantuan untuk menemukan harapan dan menemukan makna dalam kehidupannya (Wei dkk., 2016).

Harapan adalah suatu kemampuan seseorang mempercayai bahwa keadaannya saat ini merupakan keadaan yang sementara dan dapat diubah ke dalam kondisi yang lebih baik, serta suatu hal yang memotivasi untuk beralih ke kebiasaan hidup yang lebih sehat (Schiavon dkk., 2017). Harapan lebih mengarah pada upaya seseorang dalam mencapai tujuan (Fathi dkk., 2018). Sehingga harapan sembuh adalah proses kognitif pada seseorang dengan keadaan penuh motivasi yang kemudian tercipta suatu tujuan untuk mencapai kesembuhan, serta terdapat rencana dan arah positif untuk mencapai tujuan tersebut (Iriani dan Syafiq, 2017). Seseorang dengan harapan yang tinggi memiliki energi yang lebih untuk memotivasi diri berperan aktif dalam penyelesaian masalah yang berhubungan dengan penyakitnya dan terus berkembang untuk menuju kualitas hidup yang baik (Junovandy dkk., 2019).

Harapan merupakan masalah krusial pada pasien kanker. Harapan dapat dijadikan suatu proses dalam perbaikan pencapaian hasil dengan menciptakan tujuan yang berorientasi pada masa depan dan sebagai motivasi (Mahendran dkk., 2016). Harapan dapat ditingkatkan dengan pemberian dukungan sosial (Proserpio dkk., 2015). Pada saat seorang pasien dirawat dirumah sakit, dukungan sosial yang didapat bisa dari perawat dalam perilaku caring nya.

Care dan caring merupakan hal yang selalu menjadi bagian dari keperawatan. Caring adalah elemen penting dalam praktik keperawatan.
Caring mencakup perilaku ekspresif dan kegiatan instrumental, perilaku ekspresif dapat ditampilkan oleh perawat sebagai bentuk dukungan emosional melalui kesetiaan, kepercayaan diri, harapan, dan kehangatan emosional, sedangkan dalam kegiatan instrumental perawat membantu memenuhi kebutuhan dasar pasien, memberikan informasi medis, yang bertujuan untuk meningkatkan kenyamanan fisik pasien dan pasien dapat melakukan koping yang adaptif (Karlou dkk., 2014). Kehadiran seorang perawat terhadap pasien kanker dengan melibatkan perasaan penuh menghargai, kasih sayang, hormat, dan empati merupakan suatu tindakan yang bernilai dan memberikan kepuasan bagi pasien (Keliat dan Pasaribu, 2016).

Pasien kanker yang mendapatkan perilaku caring perawat yang baik, seperti sikap peduli perawat terhadap pasien, pemberian dukungan penuh terhadap pasien, perhatian dan menghormati pasien, diharapkan dapat memperbaiki tekanan psikologis yang dirasa seperti perasaan depresi dan keputusasaan, sehingga harapan pasien mengenai pembentukan kualitas hidupnya akan berjalan dengan optimal (Sulisno \& Sari, 2016).

Tujuan dari penelitian ini adalah untuk menganalisis hubungan antara perilaku caring perawat dengan tingkat harapan sembuh pada pasien kanker yang menjalani program kemoterapi di Rumah Sakit Tingkat III Baladhika Husada Jember. Hasil penelitian dapat dijadikan bahan evalusi bagi pihak manajemen Rumah Sakit Tingkat III Baladhika Husada Jember agar perilaku caring perawat dapat meningkat. Manfaat yang mungkin didapatkan pasien adalah pasien dapat berkontribusi mengenai tingkat harapan sembuh dan perilaku caring perawat sehingga perilaku caring perawat kepada pasien dapat meningkat.

\section{METODE}

Penelitian ini merupakan penelitian kuantitatif menggunakan desain deskriptif korelasional dengan pendekatan cross sectional. Teknik sampling yang digunakan adalah purposive sampling dengan total sampel berjumlah 112 responden. Populasi pada penelitian ini adalah seluruh pasien kanker yang menjalani program kemoterapi di Rumah Sakit Tingkat III Baladhika Husada Jember pada bulan Januari 2020 yaitu 316 pasien. Sampel dalam penelitian ini adalah pasien yang memenuhi kriteria inklusi meliputi pasien kanker yang menjalani 
program kemoterapi dengan minimal kunjungan ke 2 dan bersedia menjadi responden. Kriteria ekslusi meliputi pasien kanker dengan kondisi umum buruk seperti kesadaran menurun dan Tanda-tanda Vital (TTV) tidak stabil.

Uji validitas dan realibiltas dilakukan pada kuesioner CBI-24. Didapatkan nilai koefisien korelasi sebesar 0,372-0,610 dengan $r$ tabel sebesar 0,361 maka dapat disimpulkan kuesioner CBI-24 valid. Sementera uji reliabilitas didapatkan hasil 0,865 maka disebut kuesioner CBI-24 adalah reliabel. Kuesioner skala harapan telah dilakukan uji validitas dan realibilitas oleh Junovandy, dkk (2019) dengan nilai Corrected Item-Total Correlation (riX) diatas 0,3 yaitu berkisar antara 0,308-0,621 dan uji reliabilitas didapatkan nilai alpha Cronbach sebesar 0,917. Pengambilan data dilakukan oleh peneliti dengan mengunjungi pasien dan memberikan kuesioner pada pasien. Setelah data terkumpul, dilakukan analisa univariat dan bivariat. Analisa univariat terdiri dari data demografi pasien, perilaku caring perawat, dan tingkat harapan pasien. Analisa bivariat diuji menggunakan uji korelasi Kendall Tau B.

\section{HASIL}

Tabel 1 menunjukkan rata-rata usia responden adalah 50,07 tahun dengan median 50,00. Usia responden yang paling muda adalah 16 tahun dan usia yang paling tua adalah 75 tahun.

Tabel 2 menunjukkan bahwa paling banyak responden penelitian adalah berjenis kelamin perempuan yaitu sebanyak $92(82,1 \%)$ responden. Paling banyak responden memiliki status pernikahan menikah yaitu sebanyak $97(86,6 \%)$ dan pada umumnya responden memiliki status pendidikan SD yaitu sebanyak 52 (46,4\%). Untuk jenis kanker terbanyak didominasi oleh kanker payudara yaitu sebanyak $82(73,2 \%)$ dengan riwayat pengobatan antara kemoterapi dengan operasi dan kemoterapi hampir sama yaitu kemoterapi saja sebanyak 53 $(47,3 \%)$ responden dan telah melakukan operasi

Tabel 1. Gambaran Karakteristik Usia Responden di Ruang Flamboyan Rumah Sakit Baladhika Husada Jember, Tahun 2020

\begin{tabular}{lccc}
\hline $\begin{array}{c}\text { Karakteristik } \\
\text { Responden }\end{array}$ & Mean & Median & Min-Max \\
\hline Usia & 50,07 & 50,00 & $16-75$ \\
\hline
\end{tabular}

Tabel 2. Gambaran Karakteristik Responden di Ruang Flamboyan Rumah Sakit Baladhika Husada Jember, Tahun 2020

\begin{tabular}{|c|c|c|}
\hline Karakteristik Responden & Frekuensi & $\begin{array}{c}\text { Persentase } \\
(\%)\end{array}$ \\
\hline \multicolumn{3}{|l|}{ Jenis Kelamin } \\
\hline Laki-laki & 20 & 17,9 \\
\hline Perempuan & 92 & 82,1 \\
\hline \multicolumn{3}{|l|}{ Status Pernikahan } \\
\hline Lajang & 1 & 0,9 \\
\hline Menikah & 97 & 86,6 \\
\hline Duda/Janda & 14 & 12,5 \\
\hline \multicolumn{3}{|l|}{ Status Pendidikan } \\
\hline Tidak Sekolah & 9 & 8,0 \\
\hline SD & 52 & 46,4 \\
\hline SMP & 20 & 17,9 \\
\hline SMA & 24 & 21,4 \\
\hline Perguruan Tinggi & 7 & 6,3 \\
\hline \multicolumn{3}{|l|}{ Jenis Kanker } \\
\hline Kanker paru & 5 & 4,5 \\
\hline Kanker hati & 1 & 0,9 \\
\hline Kanker payudara & 82 & 73,2 \\
\hline Kanker serviks & 1 & 0,9 \\
\hline Kanker kepala dan leher & 6 & 5,4 \\
\hline Limfoma non hodgkin & 10 & 8,9 \\
\hline Kanker lain & 7 & 6,2 \\
\hline \multicolumn{3}{|l|}{ Riwayat Pengobatan } \\
\hline Operasi & 0 & 0 \\
\hline Kemoterapi & 53 & 47,3 \\
\hline Operasi dan kemoterapi & 59 & 52,7 \\
\hline Total & 112 & 100 \\
\hline
\end{tabular}

dan menjalankan kemoterapi sebanyak 59 (52,7\%) responden.

Gambar 1 menunjukkan gambaran perilaku caring perawat berdasarkan persepsi pasien yang menjalani program kemoterapi di ruang Flamboyan Rumah Sakit Baladhika Husada Jember. Sebesar $70,5 \%$ perawat telah berperilaku caring dan $29,5 \%$ menyatakan bahwa perawat kurang caring.

Gambar 2 menunjukkan bahwa distribusi item kuesioner perilaku caring perawat di ruang Flamboyan Rumah Sakit Baladhika Husada Jember ditinjau dari 4 indikator. Pada indikator assurance sebesar $42 \%$ dinilai kurang dan $58 \%$ baik. Pada indikator knowledge and skill 19,6\% dinilai kurang dan $80,4 \%$ baik, indikator respectful $12,5 \%$ dinilai kurang dan $87,5 \%$ dinilai baik. Pada indikator connectedness 


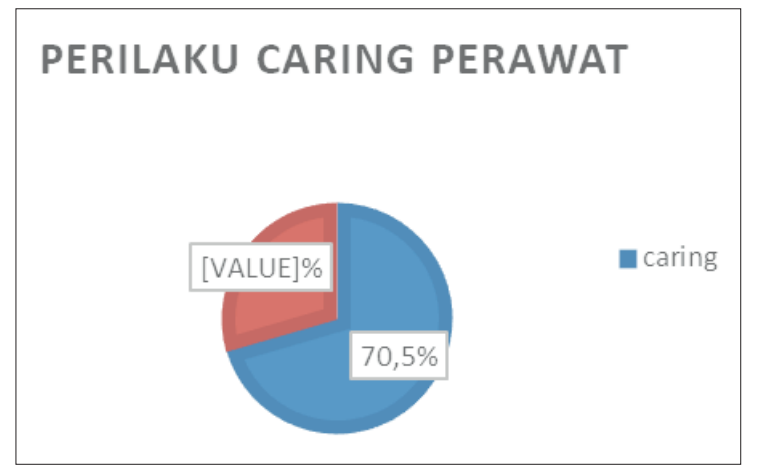

Gambar 1. Gambaran Perilaku Caring Perawat di Ruang Flamboyan Rumah Sakit Baladhika Husada Jember, Tahun 2020

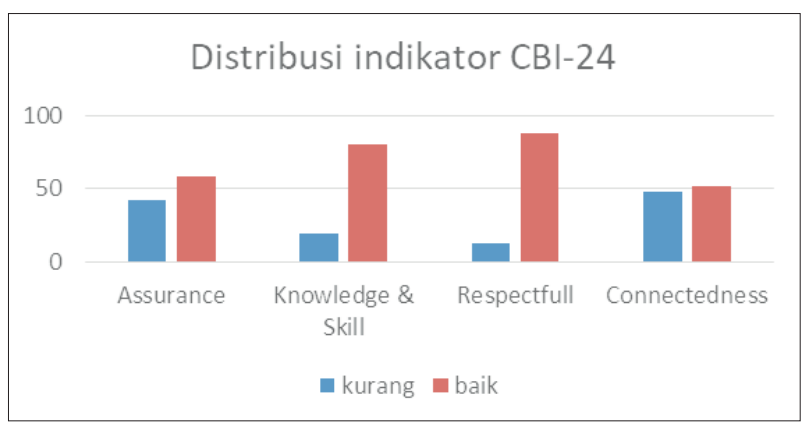

Gambar 2. Gambaran Distribusi Item Kuesioner Perilaku Caring Perawat di ruang Flamboyan Rumah Sakit Baladhika Husada Jember, Tahun 2020

sebesar $48,2 \%$ dinilai kurang dan $51,8 \%$ dinilai baik.

Gambar 3 menunjukkan gambaran tingkat harapan sembuh pasien. Dari 112 responden yang memiliki harapan sedang yaitu sebesar $62,5 \%$ responden. Pada responden yang memiliki harapan tinggi hanya sebesar $20,5 \%$ responden. Jumlah paling sedikit adalah responden dengan harapan rendah yaitu sebesar $17,0 \%$ responden.

Gambar 4 menggambarkan distribusi item kuesioner tingkat harapan sembuh pasien kemoterapi di ruang Flamboyan Rumah Sakit Baladhika Husada Jember ditinjau dari 4 indikator. Indikator goal sebesar $50,9 \%$ dinilai baik, indikator pathway thinking $63,4 \%$ dinilai baik, indikator agency thinking $68,8 \%$ dinilai baik dan indikator kombinasi pathway thinking dan agency thinking $51,8 \%$ dinilai baik.

Tabel 3 menunjukkan bahwa hasil uji bivariat dengan menggunakan uji korelasi Kendall Tau $B$ didapatkan $p$ value sebesar $<0,001$ dengan taraf signifikansi 0,05 maka $p<\alpha$. Dapat disimpulkan

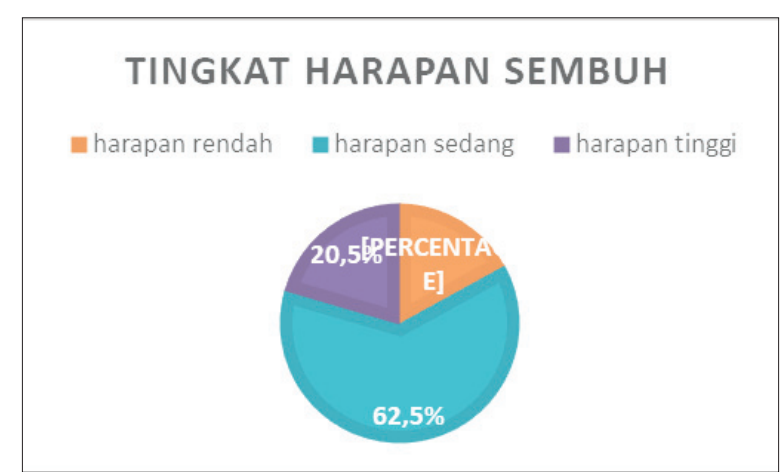

Gambar 3. Gambaran Tingkat Harapan Sembuh Pasien di ruang Flamboyan Rumah Sakit Baladhika Husada Jember, Tahun 2020

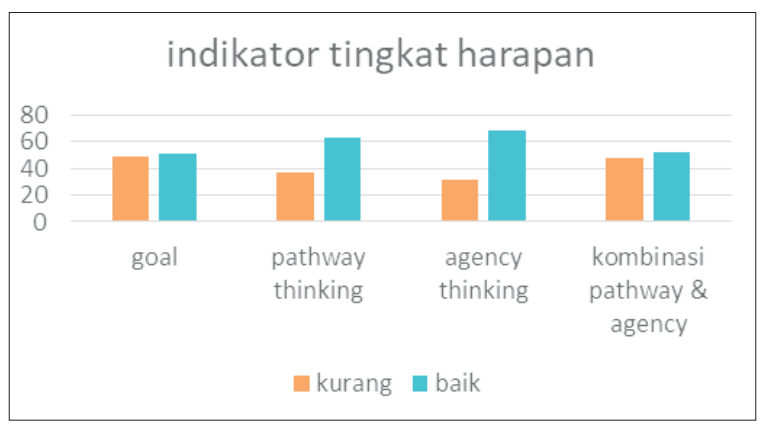

Gambar 4. Gambaran Distribusi Item Kuesioner Tingkat Harapan Sembuh Pasien Kemoterapi di Ruang Flamboyan Rumah Sakit Baladhika Husada Jember

Tabel 3. Hubungan Perilaku Caring Perawat dengan Tingkat Harapan Sembuh Pasien

\begin{tabular}{lcc}
\hline Perilaku Caring Perawat - & p value & $(\mathbf{T})$ \\
\cline { 2 - 3 } Tingkat Harapan Sembuh Pasien & $<0,001$ & 0,375 \\
\hline
\end{tabular}

bahwa Ha diterima, yang artinya terdapat hubungan yang bermakna antara hubungan perilaku caring perawat dengan tingkat harapan sembuh responden. Nilai korelasi Kendall Tau B (т) adalah 0,375 yang artinya memiliki arah positif atau searah dengan kekuatan korelasi lemah.

\section{PEMBAHASAN}

\section{Gambaran Perilaku Caring Perawat berdasarkan Persepsi Pasien}

Hasil penelitian menunjukkan dari 112 responden, $70,6 \%$ responden mempersepsikan perilaku caring perawat dalam kategori caring baik, dibandingkan dengan responden yang mempersepsikan perawat 
kurang caring adalah sebesar $29,5 \%$ responden. Hasil penelitian ini hampir sama dengan hasil penelitian yang dilakukan di ruang Asoka RSUD Jombang menunjukkan bahwa sebesar 66,7\% responden mempersepsikan perilaku caring perawat baik (Lisdiati, 2017). Penelitian ini sesuai dengan penelitian yang dilakukan di Rumah Sakit IMC Bintaro menyatakan perilaku caring perawat selama memberikan pelayanan adalah baik sebesar $75,2 \%$ responden (Manurung dan Hutasoit, 2013). Oleh karena itu, berdasarkan penelitian ini perilaku caring perawat telah dipersepsikan baik oleh pasien.

Hasil penelitian ini menunjukkan bahwa pada indikator assurance, pasien mempersepsikan baik sebesar $58 \%$. Tidak sesuai dengan penelitian sebelumnya, yaitu berdasarkan nilai humanisme/ keyakinan-harapan dan sensitivitas di RSPN Universitas Syiah Kuala Banda Aceh didapatkan hasil yang menunjukkan persepsi pasien sebanyak $100 \%$ responden menyatakan persepsi baik terhadap perilaku caring perawat tersebut (Urzia dan Jannah, 2020). Peneliti berpendapat bahwa dalam asuhan keperawatannya, perawat telah menegakkan nilai kemanusiaan dan selalu menghormati pasien sebagai individu. Perawat selalu berbicara dengan pasien saat melakukan asuhan keperawatan, namun pada faktor karatif mengembangkan sensitivitas atau kesadaran seorang perawat dalam memahami apa yang pasien butuhkan masih kurang. Maka dari itu, indikator assurance perlu ditingkatkan oleh perawat.

Indikator knowledge and skill pada penelitian ini dinilai baik untuk profesional seorang perawat. Sejalan dengan penelitian yang menyatakan bahwa perilaku caring perawat dalam pengetahuan dan keterampilan secara keseluruhan baik, yaitu sebesar 86,7\% (Muzaiyanah dan Mayasari, 2019). Peneliti berasumsi bahwa perilaku caring perawat berdasarkan indikator ini dipersepsikan baik oleh pasien, karena perawat di ruang Flamboyan Rumah Sakit Tingkat III Baladhika Husada Jember telah menunjukkan kepercayaan diri pada pasien, perawat dinilai memiliki pengetahuan dan keterampilan profesional dan mampu menggunakan alat-alat secara kompeten. Maka dari itu, hal ini sesuai dengan hasil penelitian yang menyatakan indikator perilaku caring perawat knowledge and skill adalah keseluruhan baik.

Hasil penelitian perilaku caring perawat pada indikator respectful dinilai sudah baik pada penelitian ini. Sesuai dengan penelitian yang menunjukkan sebesar $80 \%$ responden menyatakan persepsi baik terhadap perilaku perawat berdasarkan pemenuhan kebutuhan manusia dan pengungkapan ekspresi perasaan positif-negatif pasien (Ilkafah \& Harniah, 2017). Peneliti berasumsi bahwa perawat selalu mendengarkan pasien dengan penuh perhatian, perawat telah memperlakukan pasien sebagai individu dan pasien merasa perawat telah menunjukkan sikap empati dengan menanyakan apa yang dirasakan ataukah pasien perlu bantuan atau tidak. Namun, pada indikator ini pasien menilai bahwa perawat tidak setiap saat menemui pasien baik dibutuhkan atau tidak.

Pada indikator connectedness, pasien mempersepsikan perilaku perawat pada indikator ini $48,2 \%$ adalah kurang. Sesuai penelitian yang menyatakan bahwa faktor menciptakan lingkungan yang suportif, protektif dan perbaikan mental, sosiokultural dan spiritual dinilai pasien masih kurang yaitu sebesar 55,0\% (Ilkafah \& Harniah, 2017). Peneliti berpendapat bahwa perawat kurang dalam hal menghabiskan waktu bersama pasien, membantu meningkatkan perilaku sehat seperti edukasi mandiri, dan mengikutsertakan keluarga dalam perawatan. Maka dari itu, dapat diartikan bahwa perilaku caring perawat berdasarkan faktor ini masih kurang dan perlu ditingkatkan.

Perilaku caring yang dinilai masih kurang ini dapat disebabkan oleh jumlah perawat yang sangat terbatas dengan jumlah pasien yang banyak, sesuai dengan penelitian yang menyatakan bahwa rasio antara perawat dan pasien yang tidak sebanding yang dapat menyebabkan perilaku caring perawat kurang (Supriatin, 2015). Peraturan Menteri Kesehatan Republik Indonesia Nomor 340/Menkes/PER/III/2010 menentukan perbandingan ideal antara perawat dan pasien adalah 1 banding 2. Penelitian yang dilakukan di RSU Kota Banjar didapatkan perbandingan jumlah perawat dan pasien adalah 1 : 5-8 (Maharani dan Budianto, 2019). Sesuai dengan penelitian ini, di ruang Flamboyan perbandingan perawat dan pasien adalah $1: 4-8$.

Hal lain yang dapat mempengaruhi perilaku caring perawat yang kurang tersebut adalah perawat yang lebih menekankan perilaku caring fisik daripada afektif (Supriatin, 2015). Perawat lebih mengutamakan pemenuhan kebutuhan biologis sehingga pada kebutuhan psikologis, sosial, dan 
spiritual pasien kurang mendapat perhatian. Maka dari itu pasien merasa bahwa perawat kurang dalam memberikan waktunya kepada pasien, pasien merasa bahwa perawat hanya datang kepada pasien saat dibutuhkan saja dan kurang melibatkan keluarga dalam proses perawatan. Perawat seharusnya hadir untuk pasien baik dibutuhkan atau tidak untuk melihat dan membantu perkembangan pasien.

Peneliti menyimpulkan bahwa persepsi pasien terhadap perilaku caring perawat di ruang Flamboyan Rumah Sakit Tingkat III Baladhika Husada Jember sebesar $70,5 \%$ adalah baik dikarenakan dalam asuhan keperawatannya, perawat telah menerapkan perilaku caring.

\section{Gambaran Tingkat Harapan Sembuh Pasien}

Hasil penelitian menunjukkan dari 112 responden yaitu didapatkan sebesar $20,5 \%$ responden memiliki harapan tinggi dan sebesar $62,5 \%$ responden memiliki harapan sedang. Sesuai dengan penelitian sebelumnya yang dilakukan pada pasien wanita penderita kanker di Murni Teguh Memorial Hospital Medan menunjukkan bahwa hasil sebesar $62,5 \%$ harapan pasien dalam kategori sedang dan 36,2\% harapan pasien dalam kategori tinggi (Junovandy dkk., 2019). Disini peneliti berpendapat bahwa harapan pasien kanker cukup baik. Pasien mengemukakan bahwa telah memiliki tujuan untuk sembuh dari penyakit kanker yang diderita. Pasien mengungkapkan akan melakukan segala cara untuk sembuh walaupun setelah kemoterapi terdapat efek samping yang dirasakan namun pasien masih akan tetap semangat menjalaninya. Pasien juga mengemukakan bahwa masih mencari informasi untuk pengobatan dan yakin bahwa akan meraih target kesembuhan mereka.

Hasil penelitian ini menunjukkan bahwa sebesar $17,0 \%$ pasien memiliki harapan sembuh pada kategori rendah. Hasil penelitian ini tidak sejalan dengan penelitian sebelumnya yang menunjukkan tingkat harapan rendah pada pasien kanker hanya sebesar 0,7\% responden (Junovandy dkk., 2019). Berdasarkan penelitian ini peneliti berpendapat bahwa berdasarkan karakteristik demografi, terdapat hal yang dapat mempengaruhi tingkat harapan sembuh pasien adalah usia dan tingkat pendidikan. Sesuai dengan penelitian yang menyebutkan bahwa pada pasien di atas 60 tahun skor harapan menurun (Fathi dkk., 2018) dan keputusasaan berhubungan negatif dengan tingkat pendidikan (Han dkk., 2013).
Peneliti berpendapat bahwa sesuai dengan hasil penelitian ini rata-rata usia pasien adalah 50 tahun dan terdapat beberapa responden dengan usia lebih dari 60 tahun serta tingkat pendidikan terbanyak responden adalah tingkat pendidikan rendah yaitu SD. Hal ini dapat mempengaruhi skor harapan karena responden yang memiliki usia lanjut dan pendidikan yang rendah memiliki harapan yakni memiliki tujuan untuk sembuh tetapi dengan cara yang cukup terbatas, misalnya tidak mencari informasi lebih untuk pengobatan. Peneliti berasumsi bahwa responden dengan tingkat pendidikan yang tinggi akan lebih bisa mendapatkan informasi mengenai pengobatan dengan mudah, akan memiliki pemahaman yang lebih besar tentang penyakit dan pengobatan, akan memiliki pengetahuan yang lebih besar mengenai berbagai tahap perawatan sehingga mereka dapat menjalani pengobatan dengan lebih positif dan dapat melakukan berbagai cara untuk mencapai kesembuhan.

Hasil penelitian jika dilihat dari distribusi indikator tingkat harapan pasien didapatkan indikator goal atau dapat diartikan pasien telah memiliki tujuan untuk sembuh sebesar 50,9\%. Pada indikator pathway thinking $63,4 \%$ dinilai baik yang artinya pasien telah memiliki cara-cara untuk mencapai tujuan dan telah memiliki kemampuan untuk mengembangkan jalur untuk mencapai tujuan. Indikator agency thinking $68,8 \%$ dinilai baik yang artinya pasien telah memiliki kapasitas untuk tetap mencapai tujuan dengan baik dan indikator kombinasi pathway thinking-agency thinking dinilai baik sebesar $51,8 \%$.

Berdasarkan hasil ini, harapan sembuh pasien masih perlu ditingkatkan agar pasien dapat memiliki harapan dengan tingkatan yang lebih tinggi untuk mencapai kesembuhannya. Individu yang memiliki harapan tinggi akan memiliki tujuan dalam hidupnya, ia akan mampu mengembangkan cara-cara untuk mencapai tujuannya dan memiliki keyakinan bahwa ia mampu melakukan dan mengembangkan caracara untuk mencapai tujuannya (Junovandy dkk., 2019). Peneliti berpendapat bahwa perawat perlu meningkatkan harapan sembuh pasien dengan meningkatkan goal, pathway thinking, agency thinking, dan kombinasi pathway-agency thinking dengan begitu pasien dapat memiliki tujuan untuk sembuh, memiliki dan mengembangkan cara-cara untuk sembuh dan memiliki keyakinan bahwa ia mampu melakukan segala cara tersebut dan dapat mencapai tujuan untuk sembuh. 


\section{Hubungan Perilaku Caring Perawat dengan Tingkat Harapan Sembuh Pasien}

Hasil pada penelitian ini yaitu terdapat hubungan yang signifikan antara perilaku caring perawat dengan tingkat harapan sembuh pasien kanker yang menjalani program Kemoterapi di Ruang Flamboyan Rumah Sakit Baladhika Husada Jember. Nilai korelasi Kendall Tau B (T) adalah 0,375 yaitu memiliki arah positif atau searah dengan kekuatan korelasi lemah. Hubungan yang memiliki arah positif atau searah dapat diartikan dengan semakin besar nilai suatu variabel maka semakin besar nilai pada suatu variabel yang lain dan sebaliknya, yang artinya disini semakin besar nilai pada perilaku caring perawat maka semakin besar pula nilai pada harapan sembuh pasien.

Penelitian ini sesuai dengan penelitian sebelumnya yaitu menunjukkan bahwa antara perilaku caring perawat dengan tingkat harapan pasien kanker terdapat hubungan dimana nilai $p$-value didapatkan sebesar 0,013 dengan tingkat kepercayaan $(\alpha=$ $0,05)$ dinyatakan terdapat hubungan karena $p$-value $<0,05$ (Sulisno dan Sari, 2016). Peneliti berpendapat bahwa penelitian ini sesuai dan menunjukkan bahwa terdapat hubungan yang bermakna antara perilaku caring perawat dengan tingkat harapan sembuh pasien. Namun, korelasi antara perilaku caring perawat dengan tingkat harapan sembuh pasien berada pada kategori lemah.

Peneliti berpendapat bahwa penerapan perilaku caring perawat berhubungan dengan tingkat harapan sembuh pasien. Didukung oleh penelitian lain yang menyebutkan bahwa pasien yang dirawat dengan perilaku caring perawat yang baik dapat merasakan kesejahteraan emosional-spiritual, meningkatnya kemampuan fisik, keselamatan, keamanan, kenyamanan, hubungan saling percaya dan meningkatnya kerutinan dalam berobat sehingga proses penyembuhan pasien menjadi lebih cepat (Awaliah dkk., 2013). Perilaku caring perawat yang baik dapat membuat pasien menjadi nyaman dan lebih semangat dalam menjalani pengobatan, pasien merasa dihargai dan diberikan informasi-informasi yang pasien butuhkan dalam pengobatan mereka, pasien merasa senang jika perawat ramah dan pasien merasa puas apabila pertanyaannya dijawab dan dijelaskan oleh perawat.

Akan tetapi pada nilai kekuatan korelasi didapatkan nilai 0,375 yang artinya nilai kekuatan korelasi berada pada kategori lemah. Lemahnya hubungan antara perilaku caring perawat dengan tingkat harapan sembuh pasien kemungkinan dipengaruhi oleh hasil penelitian yang menunjukkan bahwa perawat dinilai kurang caring pada indikator assurance dan connectedness.

Pada indikator assurance masih dinilai kurang oleh pasien, disini berarti kehadiran seorang perawat dinilai kurang. Maka dari itu, peneliti berpendapat bahwa perilaku caring perawat yang kurang tersebut mungkin dapat mempengaruhi lemahnya hubungan dengan tingkat harapan sembuh pasien. Perawat seharusnya hadir pada pasien baik dibutuhkan atau tidak untuk memperbaiki psikososial, sosiokultural dan spiritual pasien serta dapat meningkatkan kekuatan eksistensial-fenomenologis pasien agar pasien dapat menemukan arti kehidupannya dan dapat mengendalikan diri sendiri untuk meningkatkan harapan sembuh pasien.

Penelitian lain juga mengungkapkan selain dukungan dari tenaga kesehatan, terdapat pula dukungan sosial yang dapat meningkatkan harapan pasien kanker diantaranya dukungan dari keluarga dan kerabat adalah hal yang paling berharga (Suwankhong dan Liamputtong, 2016). Maka dari itu, dukungan keluarga dan orang-orang terdekat pasien merupakan hal berharga yang dapat meningkatkan harapan pasien. Sesuai dengan penelitian yang mengatakan bahwa jika seseorang merasa dirinya dinilai, dihargai, dicintai dan didukung maka harapan seseorang dapat meningkat (Chokamy dan Razavi, 2015). Peneliti berpendapat bahwa hubungan yang baik dan dukungan dari keluarga dan orang terdekat untuk pasien sangat berarti dan dapat meningkatkan harapan pasien.

Kesejahteraan spiritualitas merupakan hal yang juga dianggap penting untuk meningkatkan harapan pasien. Sesuai dengan penelitian yang mengungkapkan bahwa praktik keagamaan juga dapat meningkatkan kesejahteraan emosional pasien kanker selama menjalani pengobatan, hal ini merupakan hal yang dapat meningkatkan harapan sembuh pasien (Suwankhong dan Liamputtong, 2016). Maka dari itu peneliti berpendapat bahwa kesejahteraan spiritualitas pasien juga dapat mempengaruhi tingkat harapan seseorang.

Penelitian lain yang membahas mengenai hubungan optimisme dengan harapan pasien dengan penyakit kronis, salah satunya kanker menyatakan bahwa optimisme seorang pasien sangat penting untuk meningkatkan harapan karena dengan optimisme pasien akan lebih memiliki kemampuan 
untuk mengelola stressor (Schiavon dkk., 2017). Disebutkan pula pasien yang kurang optimis akan mengalami perubahan psikologis yang lebih negatif dan seseorang yang memiliki sikap pesimis akan memiliki kesehatan fisik yang lebih buruk dan cenderung mengalami depresi yang lebih tinggi (Schiavon dkk., 2017).

Oleh karena itu, perawat harus mempertahankan dan meningkatkan perilaku caring kepada pasien. Selain memenuhi kebutuhan fisik pasien, perawat hendaknya memperbaiki kebutuhan psikososial dan spiritual pasien. Hendaknya perawat juga memberikan dukungan kepada keluarga agar keluarga lebih dapat memberikan dukungan kepada pasien. Perawat juga dapat memberi dukungan dan edukasi agar optimisme pasien dapat meningkat sehingga harapan pasien akan kesembuhan turut meningkat.

\section{KESIMPULAN DAN SARAN}

\section{Kesimpulan}

Kesimpulan dari penelitian ini adalah sebanyak 70,5\% responden mempersepsikan perawat di ruang Flamboyan Rumah Sakit Baladhika Husada Jember telah berperilaku caring. Sebesar $62,5 \%$ responden memiliki tingkat harapan sembuh pada kategori sedang, dan terdapat hubungan yang lemah antara perilaku caring perawat dengan tingkat harapan sembuh. Semakin baik perilaku caring perawat, semakin tinggi pula tingkat harapan sembuh pasien, dan sebaliknya.

\section{Saran}

Berdasarkan dari hasil penelitian didapatkan perilaku caring sudah baik, namun pada indikator assurance dan connectedness harus ditingkatkan karena dinilai masih kurang. Perawat dapat memberikan waktu kepada pasien minimal lima menit untuk berbicara dengan pasien kemudian membantu perkembangan pasien. Perawat seharusnya tidak fokus hanya pada kebutuhan fisik pasien, namun kebutuhan mental, sosial dan spiritual pasien hendaknya dapat juga diperhatikan. Rasio perawat dan pasien juga dapat diperbaiki agar menjadi ideal sesuai Permenkes RI. Perilaku caring perawat sangat penting untuk diterapkan dalam pelayanan keperawatan pada pasien sesuai dengan seluruh indikator sehingga kebutuhan pasien dapat terpenuhi secara komprehensif. Hal yang dapat diteliti selanjutnya adalah hubungan antara perilaku caring perawat dengan peningkatan kualitas hidup pasien atau manajemen koping pasien selama menjalani program kemoterapi. Selanjutnya, pada penelitian ini tidak dilakukan uji mengenai hal yang berkaitan dengan karakteristik demografi pasien dengan variabel. Sehingga disarankan pada penelitian selanjutnya dilakukan uji korelasi antara data demografi pasien dengan variabel tingkat harapan pasien.

\section{UCAPAN TERIMA KASIH}

Peneliti mengucapkan terimakasih kepada para responden, staf di ruang Flamboyan RS Baladhika Husada Jember, dan kelompok riset Center of Fundamental Nursing Studies (CFUNS) yang telah membantu penelitian ini.

\section{DAFTAR PUSTAKA}

Awaliah, N. Nurhaeni, dan D. Wanda. 2013. Strategi mengubah pengetahuan dan perilaku caring perawat. Indonesian Journal of Nursing Sciences and Practice. 1-8.

Chokamy, A. A. dan V. Razavi. 2015. Relationship between social support and hope and death anxiety among the old people of tehran omid cultural center. International Journal of Life Sciences. 9(2):65-70. dx.doi.org/10.3126/ijls.v9i2.12052.

Fathi, M., H. Hamzepour, J. Gammon, D. Roshani, dan S. Valiee. 2018. Hope and spiritual well-being in iranian patients undergoing chemotherapy. Journal of Evolution of Medical and Dental Sciences. 7(27):3106-3111. DOI: 10.14260/jemds/2018/698.

Firmansyah, C. S., R. Noprianty, dan I. Karana. 2019. Perilaku caring perawat berdasarkan teori jean watson di ruang rawat inap. Jurnal Kesehatan Vokasional. 4(1):33-48. hĴps://doi.org/10.22146/jkesvo.40957.

Han, Y., J. Yuan, Z. Luo, J. Zhao, J. Wu, R. Liu, dan V. Lopez. 2013. Determinants of hopelessness and depression among chinese hospitalized esophageal cancer patients and their family caregivers. Psycho-Oncology. 22(11):2529-2536. DOI: 10.1002/pon.3315.

Ilkafah \& Harniah. 2017. Perilaku caring perawat dengan kepuasan pasien di ruang rawat inap private care centre rsup dr wahidin sudirohusodo makassar nurses ' caring behaviour and patients ' satisfaction at private care centre ward in $\mathrm{dr}$. wahidin sudirohusodo hospital makassar r. Journal UMM. 8(2):138-146.

Iriani, L. P. dan M. Syafiq. 2017. Gambaran Hope Pada Penderita Tunarungu Wicara Yang Berprestasi. 2017.

Junovandy, D., R. Elvinawanty, dan W. Marpaung. 2019. Kualitas hidup ditinjau dari harapan pada pasien wanita penderita kanker. Jurnal IImiah Psikologi Terapan. 7(1):41-51. 
Karlou, C., E. Papathanassoglou, dan E. Patiraki. 2014. Caring behaviours in cancer care in greece. comparison of patients', their caregivers' and nurses' perceptions. European Journal of Oncology Nursing. 1-7. http://dx.doi.org/10.1016/j.ejon.2014.11.005.

Keliat, B. A. dan J. Pasaribu. 2016. Prinsip Dan Praktik Keperawatan Kesehatan Jiwa. Edisi Indonesia. Jakarta: Elsevier Inc.

Lisdiati, T. 2017. Komunikasi efektif dengan perilaku caring perawat terhadap pasien. Skripsi

Maharani, R. dan A. Budianto. 2019. Pengaruh beban kerja terhadap stres kerja dan kinerja perawat rawat inap dalam. Journal of Management Review. 3(2):327332. doi: http://dx.doi.org/10.25157/mr.v3i2.2614.

Mahendran, R., S. M. Chua, H. A. Lim, I. J. Yee, J. Y. S. Tan, E. H. Kua, dan K. Griva. 2016. Biopsychosocial correlates of hope in asian patients with cancer: a systematic review. BMJ Open. 6(10). doi:10.1136/ bmjopen-2016-012087.

Manurung, S. dan M. L. C. Hutasoit. 2013. Persepsi pasien terhadap perilaku caring perawat di ruang rawat inap rumah sakit. Kesmas: National Public Health Journal. 8(3): 104.

Muzaiyanah, R. dan P. Mayasari. 2019. Gambaran perilaku caring perawat di rumah sakit di banda aceh. JIM Fkep. IV(2):56-63.

Proserpio, T., A. Ferrari, S. Lo Vullo, M. Massimino, C. A. Clerici, L. Veneroni, C. Bresciani, P. G. Casali, M. Ferrari, P. Bossi, G. Galmozzi, A. Pierantozzi, L. Licitra, S. Marceglia, dan L. Mariani. 2015. Hope in cancer patients: the relational domain as a crucial factor. Tumori. 101(4):447-454. DOI: 10.5301/ tj.5000366.

Schiavon, C. C., E. Marchetti, L. G. Gurgel, F. M. Busnello, dan C. T. Reppold. 2017. Optimism and hope in chronic disease: a systematic review. Frontiers in Psychology. 7(JAN):1-10. doi: 10.3389/fpsyg.2016.02022.

Sulisno, M. dan R. P. Sari. 2016. Hubungan perilaku caring perawat dengan keyakinan dan harapan pasien kanker di rumah sakit. Media Medika Muda. 1(September):19-24.

Supriatin. 2015. Perilaku caring perawat berdasarkan faktor individu dan organisasi. Jurnal Keperawatan Indonesia. 18(3):192-198.

Suwankhong, D. dan P. Liamputtong. 2016. Social support and women living with breast cancer in the south of thailand. Journal of Nursing Scholarship. 48(1):3947. doi: 10.1111/jnu.12179.

Urzia, U. dan N. Jannah. 2020. Persepsi pasien terhadap perilaku caring perawat dirumah sakit patient perception toward the nurse caring at hospital. Jurnal IImiah Mahasiswa Fakultas Keperawatan. IV(2):132-140.

Wahyuni, Dwi; Huda Nurul; Utami, G. T. 2015. Studi fenomenologi : pengalaman pasien kanker stadium lanjut. Jurnal Online Mahasiswa. 2(2):1041-1047.

Wei, D., X.-Y. Liu, Y.-Y. Chen, X. Zhou, dan H.-P. Hu. 2016. Effectiveness of physical, psychological, social, and spiritual intervention in breast cancer survivors: an integrative review. Asia-Pacific Journal of Oncology Nursing. 3(3):226-232. DOI:10.4103 / 2347-5625.189813. 